\title{
CORRECTIONS
}

\section{Underestimating treatment benefit of lung transplantation for idiopathic pulmonary fibrosis}

The third author of this Letter (BMJ 2014;348:g24, doi:10.1136/

bmj.g24) is A B Millar, not "A B Miller" as was published.
Cite this as: BMJ 2014;348:g275

๑) BMJ Publishing Group Ltd 2014 